\title{
A Comparative Assessment of the Management of Mandibular Angle Fractures using 3D Plates and 2D Mini Plates
}

\author{
Revati Singh ${ }^{1}$, Rohit Singh ${ }^{2}$, Cheranjeevi Jayam ${ }^{3}$, Jazib Nazeer ${ }^{4}$, Mohammad A Iqubal ${ }^{5}$, Supriya Singh ${ }^{6}$
}

\begin{abstract}
Aims: The aim of this study was to compare 2D plates with 3D mini plate system in the management of mandibular angle fractures. Materials and methods: The study was conducted on 146 patients with mandibular angle fracture, who were equally divided into two groups of 73. Patients in group I were treated with 3D plating and in group II with 2D plating. In all cases, $2.0 \mathrm{~mm}$ titanium miniplates were used. The etiology of fracture, amount of mouth opening, and pain and sensory deficit were recorded. Clinical and radiographic assessment was done at 1,3 , and 6 months.

Results: The etiology of mandibular angle fracture is roadside accident (RSA) seen in 110 (75.3\%) cases, fall in 24 (16.4\%), and assault in 12 (2.6\%) cases. There was significant $(p<0.05)$ mouth opening in group I at 1 month postoperatively $(32.4 \mathrm{~mm})$ as compared to group II ( $27.5 \mathrm{~mm})$, at 3 months in group I ( $33.6 \mathrm{~mm}$ ) as compared to group I $(30.2 \mathrm{~mm})$, and at 6 months in group I $(36.4 \mathrm{~mm})$ as compared to group II (31.6 $\mathrm{mm})$. After 1 month, sensory deficit was present in six patients in group I and 10 patients in group II. After 3 months, group I had no patients and three patients in group II. Right angle fracture was found in 71 patients (group I-36, group II-35). Mandibular right angle fracture in 58 patients (group I-28, group II-30).

Conclusion: The authors found that the 3D miniplate system is more useful in the management of cases of mandibular angle fracture as compared to 2D miniplates.

Clinical significance: There has been increase in mandibular fractures in the last few years. Appropriate management with 3D miniplates may be useful in providing better treatment outcomes.

Keywords: Mandibular angle, Miniplates, Mouth opening.

The Journal of Contemporary Dental Practice (2020): 10.5005/jp-journals-10024-2787
\end{abstract}

\section{INTRODUCTION}

The number of roadside accidents (RSAs) is on rise. More commonly, four wheelers are the first one to be involved in accidents. There are various reasons, such as increase in the number of vehicles, modern fast life, and lack of traffic maintenance policy. Face being the prominent part of body, it is the first one to be traumatized. ${ }^{1}$

Mandible fracture has been seen in maximum number of cases. The most common reason for mandibular fracture can be RSA, fall, and assaults. ${ }^{2}$ Fractures of angle of the mandible, ramus, and body are more commonly encountered as compared to other parts of mandible such as condyle, symphysis, and sigmoid notch. The coronoid process is the least involved part of mandible. Apart from mandible, zygomatic bone is also the commonly fractured bone. ${ }^{3}$

Studies revealed that there is prevalence of $45-60 \%$ of mandible fractures as compared to other facial bones and angle makes up the $24-40 \%$ of all fractures in the mandible. ${ }^{4}$ The management of mandibular fracture involves immobilization of the fractured fragments. The treatment of fractured segments lasts up to 6-8 weeks, and strict liquid diet has to be followed. ${ }^{5}$ Open reduction and internal fixation is a routinely used method nowadays.

The Arbeitsgemeinschaft für Osteosynthesefragen (AO) Foundation/Association for the Study of Internal Fixation invented bone healing techniques that used dynamic compression plating. They mentioned that for better primary bone healing there should not be mobility of the fragment. Thus, the original AO technique consists of placement of double plates along the superior and
${ }^{1}$ Department of Dentistry, Patna Medical College and Hospital, Patna, Bihar, India

${ }^{2}$ Department of Prosthodontics, Crown, Bridge and Implantology, Patna Dental College and Hospital, Patna, Bihar, India

${ }^{3}$ Department of Dentistry, All India Institute of Medical Sciences, Mangalagiri, Andhra Pradesh, India

${ }^{4}$ Department of Oral Pathology, Patna Dental College and Hospital, Patna, Bihar, India

${ }^{5}$ Department of Oral Medicine and Radiology, Patna Dental College and Hospital, Patna, Bihar, India

${ }^{6}$ Private Practitioner, Department of Oral Medicine and Radiology, Patna, Bihar, India

Corresponding Author: Revati Singh, Department of Dentistry, Patna Dental College and Hospital, Patna, Bihar, India, Phone: +91 8210356292, e-mail: revateesingh@gmail.com

How to cite this article: Singh R, Singh R, Jayam C, et al. A Comparative Assessment of the Management of Mandibular Angle Fractures using 3D Plates and 2D Mini Plates. J Contemp Dent Pract 2020;21(4):400-403. Source of support: Nil

Conflict of interest: None

inferior borders of the mandible. ${ }^{6}$ Earlier 2D plating was used but nowadays, the 3D plating system has led to improvement in orthopedics which resulted in favorable results. ${ }^{7}$ The geometry of the 3D mini plate theoretically allows for an increased number of screws, resistance against torque forces, etc. ${ }^{8}$ Considering this, this study aimed at comparing 2D plates with 3D mini plate system in the management of mandibular angle fractures (Fig. 1).

(c) The Author(s). 2020 Open Access This article is distributed under the terms of the Creative Commons Attribution 4.0 International License (https://creativecommons. org/licenses/by-nc/4.0/), which permits unrestricted use, distribution, and non-commercial reproduction in any medium, provided you give appropriate credit to the original author(s) and the source, provide a link to the Creative Commons license, and indicate if changes were made. The Creative Commons Public Domain Dedication waiver (http://creativecommons.org/publicdomain/zero/1.0/) applies to the data made available in this article, unless otherwise stated. 


\section{Materials and Methods}

The study was conducted in the Department of Dentistry in $\mathrm{PMCH}$ and PDCH, Patna, Bihar. It consisted of 146 patients who visited to the department for the management of mandibular angle fracture of both genders. All patients were well informed regarding the study, and the written consent was obtained (Fig. 2).

Patient data, such as name, age, and gender, were recorded. Inclusion criteria were patients aged 20-70 years of both gender and patients with American Society of Anesthesiologists physical status classification system I (ASA I) and American Society of Anesthesiologists physical status classification system II (ASA II) without any contraindication for surgery or anesthesia. Exclusion criteria were patients with preexisting musculoskeletal disease or neurologic disease and patients with midface fractures.

Depending upon the plating system, patients were equally divided into two groups of 73. Patients in group I were treated with 3D plating and in group II with 2D plating. In all cases, $2.0 \mathrm{~mm}$ titanium miniplates were used (Fig. 3).

General physical examination was done to assess injury of thorax, abdomen, genitourinary tract, or long bones. Panoramic radiographs were taken to see the type of fracture.

Fracture site at mandibular angle was approached extraorally through submandibular incision and open reduction and internal

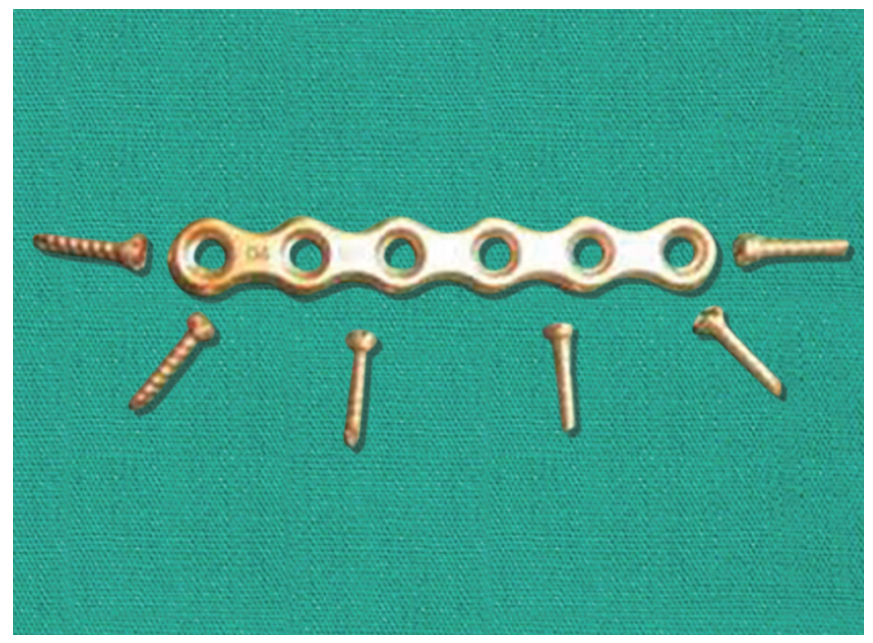

Fig. 1: 2D miniplate

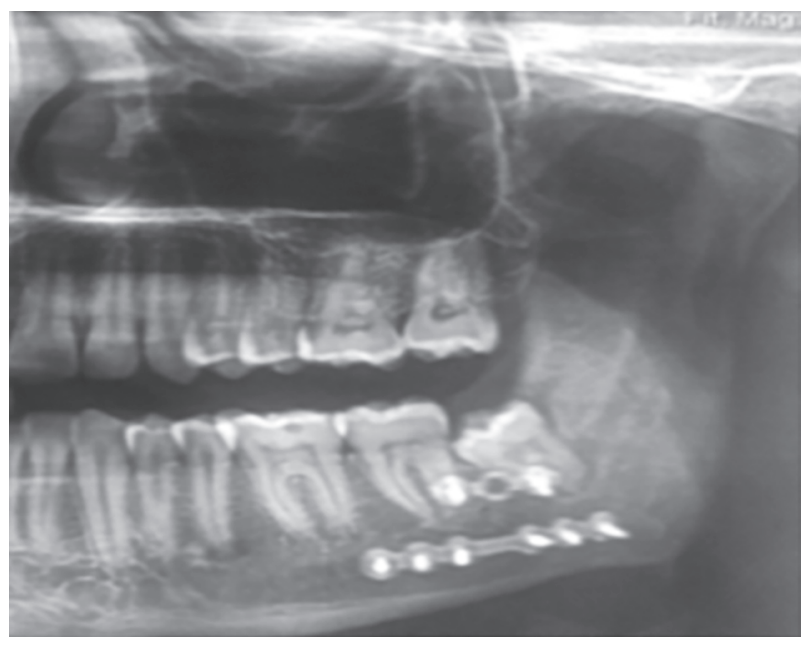

Fig. 3: 2D miniplate orthopantomograph fixation were performed with 3D miniplates in group I patients and 2D miniplates in group II patients. A single oral and maxillofacial surgeon performed all the procedures under aseptic surgical procedures. Postoperative panoramic radiographs were taken to assess fracture reduction and correct insertion of plates. Patients were prescribed antibiotics amoxicillin $500 \mathrm{mg}$ three times per day (TDS) and analgesics diclofenac sodium $400 \mathrm{mg}$ TDS for 5 days (Fig. 4).

The etiology of fracture, amount of mouth opening, and pain and sensory deficits were recorded. Clinical and radiographic assessment was done at 1, 3, and 6 months.

\section{Statistical Analysis}

Results were expressed as mean $\pm \mathrm{SD}$. Chi-square test was used for the study using SPSS version 21.0. $p$ value less than 0.05 was considered significant.

\section{Results}

Table 1 shows that in group I, 3D miniplates and in group II, 2D miniplates were used. There were 43 males and 30 females in group I and 46 males and 27 females in group II.

Table 2 shows that the etiology of mandibular angle fracture is RSA seen in 110 (75.3\%) cases, fall in 24 (16.4\%), and assault

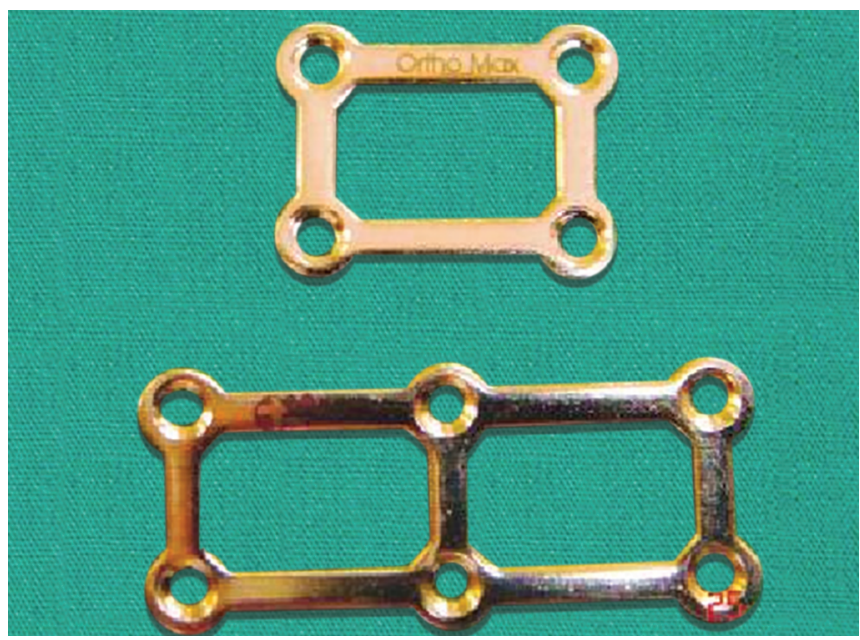

Fig. 2: 3D miniplate

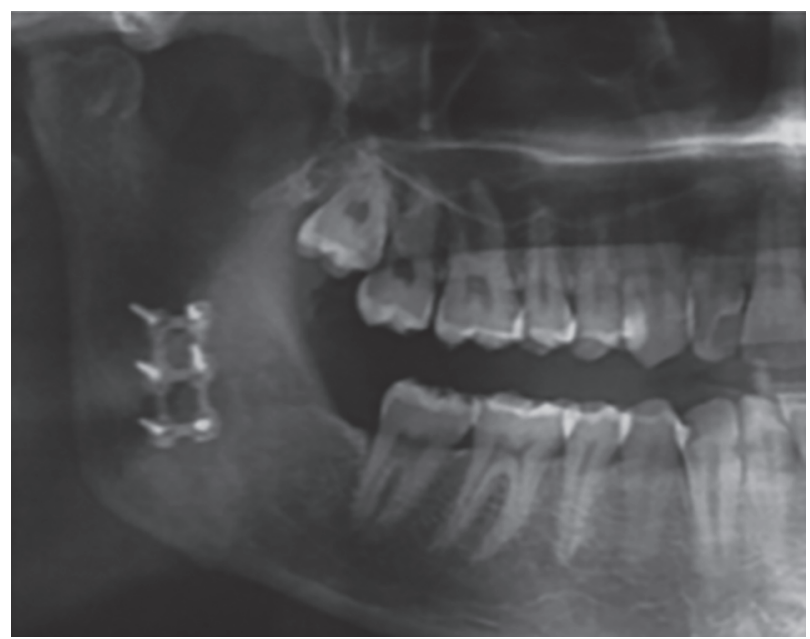

Fig. 4: 3D miniplate orthopantomograph 
Table 1: Distribution of patients

\begin{tabular}{lll}
\hline & Group I & Group II \\
\cline { 2 - 3 } Gender & 3 D miniplates & 2D miniplates \\
\hline Male & 43 & 46 \\
Female & 30 & 27 \\
\hline
\end{tabular}

Table 2: Etiology of mandibular angle fracture

\begin{tabular}{lll}
\hline Etiology & Number & p value \\
\hline RSA & $110(75.3 \%)$ & 0.01 \\
Fall & $24(16.4 \%)$ & \\
Assault & $12(2.6 \%)$ & \\
\hline
\end{tabular}

Table 3: Assessment of mouth opening in both groups

\begin{tabular}{llll}
\hline & Group I & Group II & \\
\cline { 2 - 3 } Period & Mean $(\mathrm{mm})$ & Mean $(\mathrm{mm})$ & p value \\
\hline Preoperative & 24.5 & 24.8 & 0.51 \\
1 month & 32.4 & 27.5 & 0.05 \\
3 months & 33.6 & 30.2 & 0.04 \\
6 months & 36.4 & 31.6 & 0.02 \\
\hline
\end{tabular}

Table 4: Sensory deficit in both groups

\begin{tabular}{llll}
\hline Follow-up & Group I & Group II & p value \\
\hline 1-month postoperative & 6 & 10 & 0.01 \\
3-month postoperative & 0 & 3 & 0.01 \\
6-month postoperative & 0 & 0 & 0 \\
\hline
\end{tabular}

Table 5: Postoperative treatment outcome

\begin{tabular}{llll}
\hline Postoperative & Group I & Group II & p value \\
\hline Complete healing & 71 & 68 & 0.04 \\
Color changes & 72 & 67 & 0.05 \\
\hline
\end{tabular}

in $12(2.6 \%)$ cases. The difference was found to be significant $(p<0.05)$.

Table 3 shows that there was significant $(p<0.05)$ mouth opening in group I at 1 month postoperatively $(32.4 \mathrm{~mm})$ as compared to group II (27.5 mm), at 3 months in group I (33.6 mm) as compared to group I ( $30.2 \mathrm{~mm})$, and at 6 months in group I (36.4 $\mathrm{mm})$ as compared to group II (31.6 mm). Thus, there was better

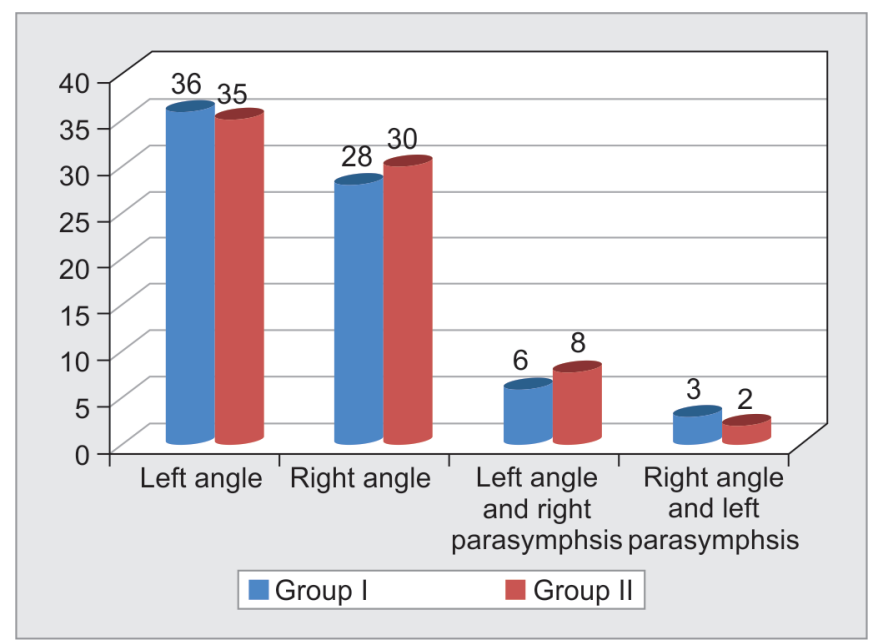

Fig. 5: Different types of fractures mouth opening postoperatively in group I (3D plating) as compared to group II (2D plating).

Table 4 shows that after 1 month sensory deficit was present in six patients in group I and 10 patients in group II. After 3 months, group I had no patients and three patients in group II. After 6 months, both groups had no patients. The difference was significant $(p<0.05)$. Thus, there was less sensory deficit postoperatively in group I (3D plating) as compared to group II (2D plating).

Table 5 shows that there was complete healing seen in 71 patients in group I and 68 in group II and color change in 72 in group I and 67 in group II. The difference was significant $(p<0.05)$.

Figure 5 shows that right angle fracture was involved in 71 patients (group I-36, group II-35). Right angle fracture in 58 patients (group I-28, group II-30) and left angle and right parasymphysis fracture in 14 cases (group I-6, group II-8). Right angle and left parasymphysis fracture was seen in five patients (group $1-3$, group II-2). The difference was nonsignificant $(p>0.05)$.

We found that mean pain assessed on visual analog scale (VAS) preoperatively, in group I was 4.5 and in group II was 4.7, at 1 month it was 2.1 in group I and 2.9 in group II, at 3 months it was 0.82 in group I and 1.34 in group II, and at 6 months it was 0.41 in group I and 0.98 group II. The difference was significant $(p<0.05)$. There was less pain score recorded on VAS postoperatively in group I (3D plating) as compared to group II (2D plating).

Thus, there was better patient response with 3D plating as compared to 2D plating in mandibular angle fracture (Fig. 6).

\section{Discussion}

Mandibular fractures are commonly seen among facial bone fractures. The advancement in techniques and methods in the management of mandibular fractures has led better patient outcome and favorable results. ${ }^{9}$ There are different methods of direct fixation with an open approach. AO bicortical plating system such as twodimensional miniplating system and screws and 3-dimensional miniplating system are recent methods for mandibular angle fractures. ${ }^{10,11}$ This study aimed at comparing 2D plates with 3D mini plate system in the management of mandibular angle fractures.

In this study, we enrolled 146 patients who visited to the department for the treatment of mandibular angle fracture which was confirmed by taking panoramic radiographs. Based on the plating system used, there were 73 patients each in group I (3D)

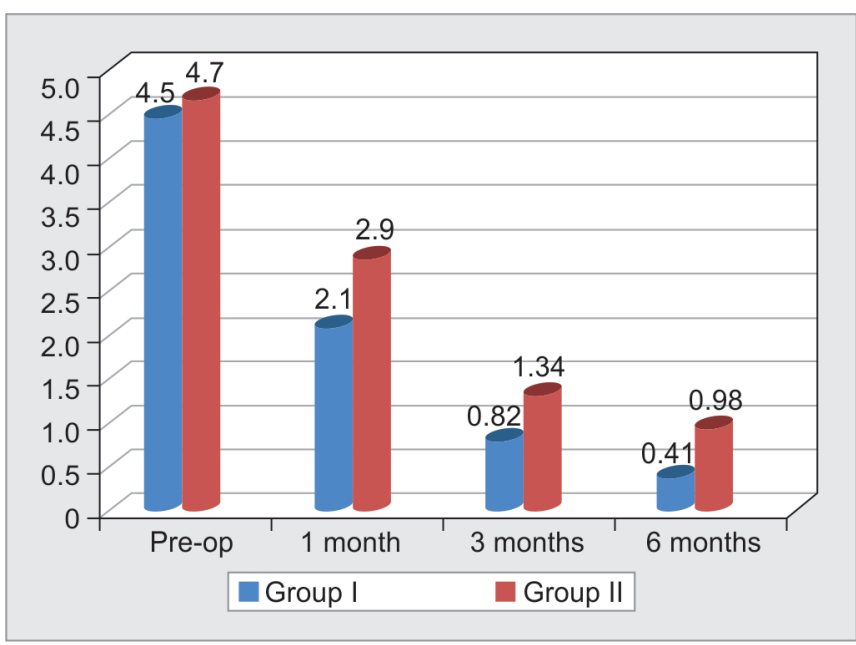

Fig. 6: Assessment of pain in both groups 
and group II (2D). Group I comprised of 43 males and 30 females and group II had 46 males and 27 females.

Mittal et al. ${ }^{12}$ conducted a study in which 30 patients with noncomminuted mandibular parasymphysis fractures were divided into $2 \mathrm{~mm} 3 \mathrm{D}$ and $2 \mathrm{~mm} 2 \mathrm{D}$ miniplate systems, respectively. All patients were systematically monitored at 1st, 2nd, 3rd, 6th week, $3 \mathrm{rd}$, and 6th month postoperatively. The results showed that one patient in each group had postoperative infection, occlusion derangement, and mobility. In group I, one patient had paresthesia while in group II, two patients had paresthesia. There was no implant failure in any group. There was no statistically significant difference between 3D and 2D miniplate systems in all the recorded parameters at all the follow-ups.

We observed that the etiology of mandibular angle fracture is RSA seen in 110 cases, fall in 24, and assault in 12 cases. In maximum cases, right angle fracture was involved in 36 patients in group I and 35 in group II followed by right angle fracture in 28 in group I and 30 in group II patients. Left angle and right parasymphysis fracture in 14 cases, and right angle and left parasymphysis fracture was seen in 5 patients.

Singh et al. ${ }^{13}$ found that out of 70 patients, $77.14 \%$ corresponded to the age group of $15-30$ years and $82.85 \%$ were males. Road traffic accident (80\%) was the leading cause of fracture. The time required to adapt and fix the miniplates was slightly more than 3D plates and the results were statistically significant. Skeletal and occlusal stability was maintained in both groups.

We found that mean pain assessed on VAS in both groups preoperatively, at 1 month, 3 months, and 6 months was significant $(p<0.05)$. Group I had lower score than group II. We also observed that cases of sensory deficit were more in group ll as compared to group I.

It is found that a thin cross-sectional area relative to the body, symphysis, and parasymphysis anteriorly, and the presence of the third molars is among various causes leading to mandibular angle fracture. The angle of mandible is where there is abrupt change in the shape from horizontal body to vertical rami which implies that this region might be subjected to more complex force than a more linear geometry shape. ${ }^{14}$

Barde et al. ${ }^{15}$ conducted a study in 40 patients with anterior mandibular fractures. Group I consisting of 20 patients in whom 3D plates and group II consisting of other 20 patients in whom 4 holes straight plates were used. It was found that the mean operation time for group II was more compared to group I. There was significantly greater pain on day of surgery and at 2 nd week for group II patients but there was no significant difference between the two groups at 4th week. The postoperative infection, occlusal disturbance, wound dehiscence, postoperative mobility at the facture site, and neurological deficit were statistically insignificant.

The limitations of the study are the small sample size and the limited follow-up period.

\section{ConcLusion}

The authors found that 3D miniplate system is more useful in the management of cases of mandibular angle fracture as compared to $2 \mathrm{D}$ miniplates.

\section{Future Scope}

Large-scale studies may provide better results.

\section{References}

1. Sawatari $\mathrm{Y}, \mathrm{Marwan} \mathrm{H}$, Alotaibi F, et al. The use of three-dimensional strut plates for the management of mandibular angle fractures: a retrospective analysis of 222 patients. Int J Oral Maxillofac Surg 2016;45(11):1410-1417. DOI: 10.1016/j.ijom.2016.05.023.

2. Chhabaria G, Halli R. Evaluation of $2.0-\mathrm{mm}$ titanium three dimensional curved angle strut plate in the fixation of mandibular angle fractures- a prospective clinical and radiological analysis. Craniomaxillofac Trauma Reconstr 2014;7(2):119. DOI: 10.1055/s-00341371002.

3. Cillo J, Ellis E. Management of bilateral mandibular angle fractures with combined rigid and nonrigid fixation. J Oral Maxillofac Surg 2014;72:106. DOI: 10.1016/j.joms.2013.07.008.

4. Almoraissi EA, Ellis III E. What method for management of unilateral mandibular angle fractures has the lowest rate of postoperative complications? A systematic review and meta-analysis. J Oral Maxillofac Surg 2014;72(11):2197. DOI: 10.1016/j.joms.2014.05. 023.

5. Afrooz PN, Bykowski MR. The epidemiology of mandibular fractures in the United States, part 1: a review of 13,142 cases from the US National Trauma Data Bank. J Oral Maxillofac Surg 2015;73:2361. DOI: 10.1016/j. joms.2015.04.032.

6. Lee JH. Treatment of mandibular angle fractures. Arch Craniofac Surg 2017;18(2):73-75. DOI: 10.7181/acfs.2017.18.2.73.

7. Pandey V, Bhutia O, Nagori SA, et al. Management of mandibular angle fractures using a $1.7 \mathrm{~mm}$ 3-dimensional strut plate. J Oral Biol Craniofac Res 2016;6(1):36-41. DOI: 10.1016/j.jobcr.2015.11.001.

8. Budhraja NJ, Shenoi RS, Badjate SJ, et al. Three-dimensional locking plate and conventional miniplates in the treatment of mandibular anterior fractures. Ann Maxillofac Surg 2018;8(1):73-77. DOI: 10.4103/ ams.ams_175_17.

9. Morris C, Bebeau NP. Mandibular fractures: an analysis of the epidemiology and patterns of injury in 4,143 fractures. J Oral Maxillofac Surg 2015;73(5):951. DOI: 10.1016/j.joms.2015.01.001.

10. Wusiman P, Yarbag A, Wurouzi G, et al. Three dimensional versus standard miniplate fixation in management of mandibular fractures: a systematic review and meta-analysis. J Craniomaxillofac Surg 2016;44(10):1646-1654. DOI: 10.1016/j.jcms.2016.07.027.

11. Giri KY, Singh AP, Dandriyal R, et al. Incidence and pattern of mandibular fractures in Rohilkhand region, Uttar Pradesh state, India: a retrospective study. J Oral Biol Craniofac Res 2015;5(3):140-145.

12. Mittal Y, Varghese KG, Mohan S, et al. A comparative study of 3-dimensional titanium versus 2-dimensional titanium miniplates for open reduction and fixation of mandibular parasymphysis fracture. J Maxillofac Oral Surg 2016;15(1):93-98. DOI: 10.1007/s12663-0150780-7.

13. Singh R, Shahi AK, Prajapati VK, et al. Comparative study of 3 dimensional and standard miniplate in management of anterior mandibular fractures. Int J Contemp Med Res 2019;6(8):5-11.

14. Mishra N, Thakkar N, Kar I, et al. 3-D miniplates versus conventional miniplates in treatment of mandible fractures. J Maxillofac Oral Surg 2017. 1-8.

15. Barde DH, Mudhol A, Ali FM, et al. Efficacy of 3-dimensional plates over Champys miniplates in mandibular anterior fractures. J Int Oral Health 2014;6(1):20-26. 